\section{MINDFULNESS STRESS REDUCTION \& SELF HARM INTERVENTION FOR RECOVERY COACHES \& SUBSTANCE USING CLIENTS}

${ }^{1}$ Quintin L Williams, ${ }^{2}$ Kyra Shannon. 'University of Illinois at Chicago, Department of Mechanical and Industrial Engineering, ${ }^{2}$ University of Illinois at Chicago, Department of Public Administration

\subsection{6/injuryprev-2016-042156.552}

Background Nearly half of all children in foster care in the state of Illinois are removed from parents with serious substance abuse problems (Ryan and Huang, 2012). Treatment Alternatives for Safe Communities (TASC), provides health and human services to underserved populations who need treatment for alcohol, drug, and mental health problems and advocates through use of Recovery Coaches for this population in courts, jails, prisons, and child welfare systems.

Methods We have developed an eight week training program on Mindfulness Based Stress Reduction practices, adapted for Recovery Coaches, who work with substance involved parents seeking to regain custody of their children. The training program will develop stress reduction techniques designed to reduce compassion fatigue, burnout, and also techniques designed to enhance interpersonal awareness among Recovery Coaches to enhance the working alliance and improve client outcomes.

Results Presently, the Recovery Coach program have serviced over 4,000 substance abusing parents with trying to regain custody with over 5,000 children. The study includes surveys with 21 Recovery Coaches (11 cases and 10 controls); and 300 clients (10 clients per coach). Analyses have determined the change in baseline and three month post intervention measures of mindfulness, compassion fatigue, burnout and secondary trauma among Recovery Coaches trained in MBSR compared to Recovery Coaches who did not receive the intervention. Thirty-eight percent of the clients completed treatment during this reporting period, $26 \%$ are in treatment, $22 \%$ are currently not in treatment, and $14 \%$ failed treatment or were non-compliant.

Conclusions This study contributes to the development of the Recovery Coach Model by examining intricacies of the clientworker engagement process that facilitates positive coach/client outcomes with the goal of preventing self harm activities and domestic violence among families dealing with substance use.

\section{THE THEORY OF PLANNED BEHAVIOUR FOR DRINKING AND DRIVING: AN EMPIRICAL VALIDATION USING DATA COLLECTED IN TWO CHINESE CITIES FROM 2010 TO 2014}

Qingfeng Li, Huan He, Adnan A Hyder. Johns Hopkins International Injury Research Unit, Department of International Health, Johns Hopkins Bloomberg School of Public Health

\subsection{6/injuryprev-2016-042156.553}

Background Road traffic crashes are mostly attributable to violations of traffic regulations. Particularly, despite its proven risk, the violation of drinking and driving regulation is still pandemic in many countries and leads to a large number of traffic injuries and fatalities. A better understanding of the factors affecting drinking and driving behaviour is crucial to developing effective interventions to reduce the risk. The most commonly used theoretical model to predict this behaviour is the theory of planned behaviour (TPB). We aimed to assess the ability of this theory in explaining the violation of drinking and driving regulation.
Methods As part of an international road safety consortium, a range of interventions, including social media campaigns, advocacy for legislative change, and law enforcement training, were implemented in two Chinese cities (Suzhou and Dalian) from 2010 to 2014. To monitor and evaluate the project, surveys on motor vehicle's knowledge, attitude and practice (KAP) were regularly conducted from representative samples in both cities. The outcome is whether the respondent has driven a motor vehicle after drinking alcohol in the past 30 days. About 30 indicators measuring drivers' KAP and demographic information were collected.

Results Totally nine rounds of surveys were completed in each city, covering 11,362 drivers. Overall, about $1.9 \%$ of the respondents have driven a motor vehicle after drinking alcohol in the past 30 days. Multivariate logistic regressions show that female drivers are $2.4 \%$ (95\% CI: $-3.4 \%,-1.5 \%)$ less likely to drive after drinking than male drivers. The risk is $1.9 \%$ (95\% CI: $-3.1 \%,-0.8 \%$ ) higher among drivers who believe the penaty if caught drinking and driving is heavy than those who believe it is light. The attitude toward drinking and driving and perceived chance of being caught if violated have the largest direct effects. Drivers with correct attitude towards drinking and driving are 27\% (95\% CI: $-28.7 \%,-25.3 \%$ ) less likely to do that than drivers who underestimated the risk of drinking and driving. Compared with drivers who believe the chance of being caught is less than $30 \%$, other drivers have a statistically significantly reduced prevalance of drinking and driving.

Conclusions The remarkable consistency between the theory and data indicates that the TPB theory is strongly supported. Social marketing campaign to educate the drivers about the risk of driving and driving, combined with strengthening enforcement to increase the likelihood of being caught if drinking and driving, may be an effective strategy to prevent the violations.

\section{ALCOHOL USE AND CRIMINAL VIOLATIONS IN VIET NAM: POLICY IMPLICATIONS FOR ALCOHOL CONTROL}

${ }^{1}$ Nam Nguyen Phuong, ${ }^{2}$ Trung Nguyen Thanh, ${ }^{2}$ Dzung Dinh Thi Phuong. 'WHO, Vietnam; ${ }^{2}$ People's Police Academy, Vietnam

\subsection{6/injuryprev-2016-042156.554}

Background Alcohol use is highly prevalent in Viet Nam, especially among males. Results from a national survey in 2010 showed $70 \%$ of Vietnamese males are drinkers, among them $24.1 \%$ drinks at harmful level.

Methods This study was conducted in partnership with the People's Police Academy (PPA) by collecting data from 11 provinces and cities in Viet Nam on all criminal violations 2010 to 2014. A total of 60,657 criminal cases were collected for analysis on association with alcohol use.

Results Out of 60,657 criminal cases, 2,621 cases were identified as associated with alcohol use, accounting for $4.3 \%$. About $71 \%$ of the cases are in the age group of 16 to $30,24 \%$ and $5 \%$ are in the groups of 30-45 and above 45 respectively.

The most common time of intoxicated cases and public disorder and crime is in the evening between the time frame of 18.0024.00 hours, accounting for $61 \%$ of total cases. In addition, data showed that 1 in 5 criminal cases happened after 24.00 hours.

Policy implications It's essential to develop and implement a strong national alcohol policy to control the availability and consumption of alcohol in the country to reduce the harmful use of alcohol and criminal violations. It's also crucial to focus alcohol 